\title{
Constant Hamès (Dir.), Coran et talismans. Textes et pratiques magiques en milieu musulman
}

Paris, Karthala, coll. « Hommes et Sociétés », 2007, 416 p.

Jean-Louis Triaud

\section{OpenEdition}

\section{Journals}

Édition électronique

URL : http://journals.openedition.org/assr/25505

DOI : $10.4000 /$ assr.25505

ISSN : $1777-5825$

Éditeur

Éditions de l'EHESS

Édition imprimée

Date de publication : 30 décembre 2013

Pagination : 213

ISSN : 0335-5985

Référence électronique

Jean-Louis Triaud, « Constant Hamès (Dir.), Coran et talismans. Textes et pratiques magiques en milieu musulman », Archives de sciences sociales des religions [En ligne], 164 | 2013, mis en ligne le 03 mars 2014, consulté le 21 septembre 2020. URL : http://journals.openedition.org/assr/25505 ; DOI : https://doi.org/10.4000/assr.25505

Ce document a été généré automatiquement le 21 septembre 2020.

(c) Archives de sciences sociales des religions 


\section{Constant Hamès (Dir.), Coran et} talismans. Textes et pratiques magiques en milieu musulman

Paris, Karthala, coll. « Hommes et Sociétés », 2007, 416 p.

Jean-Louis Triaud

\section{RÉFÉRENCE}

Constant Hamès (Dir.), Coran et talismans. Textes et pratiques magiques en milieu musulman, Paris, Karthala, coll. «Hommes et Sociétés », 2007, 416 p. 
1 Il existe depuis longtemps une petite confrérie discrète qui s'est passionnée à contre-courant pour la magie et les talismans islamiques. À contre-courant par rapport aux sciences humaines, où longtemps un rationalisme de bon aloi écartait le chercheur de telles superstitions. À contre-courant, ensuite, de l'orientalisme bon teint, attaché à l'étude des grands textes normatifs. À contre-courant, enfin, par rapport aux gardiens du dogme, pour qui ces pratiques représentent des déviations blâmables. Le terme « magie » lui-même est si connoté qu'il paraît étranger aux catégories scientifiques. Dès la première page de l'introduction, par Louis Brenner, il figure entre guillemets pour mieux conjurer tout reproche en la matière. On retiendra la définition opportune donnée pour couvrir ce champ miné: "ensemble d'idées et d'actions qui modifient le cours naturel des événements ».

2 Constant Hamès, qui en est l'auteur et dirige ce volume, est, de longue date, un des adeptes reconnus de cette confrérie de chercheurs. L'Afrique subsaharienne et Madagascar constituent leur espace commun. Des observateurs hâtifs voient volontiers dans ces pratiques une simple contamination du message islamique par des imprégnations animistes africaines. Or il n'en est rien. La magie islamique est saturée d'écrits, d'écrits coraniques principalement, qui la placent en rupture avec les différentes formes de sorcellerie subsaharienne. La demande sociale de protection et de guérison est partout la même, les moyens ne le sont pas. Cette fonction de l'écrit est centrale dans la composition des formules, mais c'est l'énergie qu'on lui attribue qui compte, non sa lecture. Cette énergie ne peut elle-même être transmise que par un rituel où l'oral prend toute sa place, si bien qu'il est impossible de séparer le texte qui mobilise les forces et la parole qui les insuffle.

3 La racine $s-h-r$ et tous ses dérivés, désignent, en arabe, les opérations de type magique. Le Coran et la Sunna les condamnent et tout l'art des exégètes va être d'établir une distinction entre une magie licite et une magie illicite. $C$. Hamès ouvre le volume par un chapitre consacré à la « notion de magie dans le Coran ». Francesco Zappa l'illustre par l'examen d'un commentaire coranique d'al-Qurtubî (XIII ${ }^{\mathrm{e}}$ siècle). Face à la condamnation sans appel qui figure dans un hadith transmis par Tirmidhi : « La peine établie contre le magicien est la peine de mort ", on peut admirer la manière dont alQurtubî contourne l'obstacle. Déjà, le juriste malikite Ibn Abî Zayd al-Qayrawânî ( $\mathrm{x}^{\mathrm{e}}$ siècle) avait affirmé qu'« il n'y a pas de mal à se préserver par des charmes contre le mauvais œil et autres choses de ce genre »- les formules coraniques qu'ils contiennent suffisant, à ses yeux, à en garantir l'orthodoxie.

4 Un hadith affirme que "le rêve est une partie de la prophétie ». C'est dire son importance dans la tradition musulmane comme le montre Pierre Lory qui étudie « l'interprétation des rêves dans la culture musulmane » et rappelle la place qu'occupe cette discipline dans le corpus islamique. On pourrait y ajouter un lien particulier avec le soufisme. «Le point de vue d'Ibn Khaldoun » (Abderrahmane Lakhsassi) introduit 
une clef supplémentaire. Pour Ibn Khaldoun, qui peine à élaborer des critères clairs permettant de définir la magie licite, c'est finalement l'intention morale qui va déterminer la nature de l'action. Mauvais œil et talismans, karâmât et mu'jizat sont ainsi passés au crible. Globalement, seule la magie qui est agie par la puissance divine est licite. Un bon discernement est donc nécessaire à cet effet.

Après l'étude des textes de référence vient "l'étonnante pléthore des pratiques magiques» (L. Brenner), qui échappent largement aux tentatives normatives. La contribution d'Ahmed Rahal sur «la tradition talismanique en Tunisie », à partir d'un manuel du XIX ${ }^{e}$ siècle, est à la charnière de la théorie et des exercices pratiques. Il y est question de la confection d'amulettes à usage thérapeutique et propitiatoire. Diagnostics, numérologie et carrés magiques y prennent toute leur place. Ce sont ensuite l'étude de ces objets étonnants que représentent les tuniques talismaniques au Sénégal (Alain Epelboin, Constant Hamès et Anne Raggi), protections réputées très puissantes dont l'une d'entre elles, couverte d'écritures, illustre magnifiquement le volume. Ces objets et beaucoup d'autres du même type proviennent des dépôts d'ordures aux limites de Dakar et sont conservés à Paris dans la collection ALEP (Alain Epelboin), véritable mine d'objets de protection abandonnés. Yahya Ould El-Bara traite des "morsures de serpent chez les Bidân de Mauritanie ». Il montre comment, à côté d'une puissante tradition savante dans ce pays, tout un secteur de "maraboutsguérisseurs, charismatiques ou besogneux " s'est institué pour répondre à la demande, face au serpent, "la créature qui résume le mal », véritable «hantise pour l'éleveur nomade » qui marche pieds nus. Techniques de prévention et de guérison, formules, incantations, carrés magiques composent cet arsenal. Benjamin Soares considère l'activité d'un fabricant et commerçant d'amulettes au Mali, disciple et assistant d'un cheikh tijani. Il cite aussi plusieurs pratiques de consultation et de protection: nasi (l'eau qui a lavé une formule écrite), sadaqa (aumône/sacrifice), hijâb (nom générique pour les amulettes et talismans), khalwa (retraite), istikhâra (technique de recherche d'inspiration divine). C'est ainsi un florissant marché des ressources occultes qui surgit, lequel répond à une demande omniprésente. Philippe Beaujard présente le dossier des "manuscrits arabico-malgaches (sorabe) du Sud-Est de Madagascar». Il montre comment ces manuscrits "restent largement hermétiques", tant il est vrai que ces textes «sont inséparables d'une connaissance transmise oralement». L'astrologie y tient une place majeure. L'étude d'un "charme de guérison Antemoro " complète le dossier. Sophie Blanchy, qui traite des «textes islamiques protecteurs aux Comores : transmissions et usages ", passe en revue les ouvrages de référence en circulation, dont le fameux Shams al Ma'ârif de l'Algérien al-Bûnî (al-Malikî al-Amazighî), m. au début du $\mathrm{XIII}^{\mathrm{e}}$ siècle, puis elle dresse des portraits de spécialistes et commente des exemples de pratiques, où se combinent la "récitation » et le «remède ». Anne Regourd présente "deux coupes magico-thérapeutiques» au nord du Yémen, biens waqf conservés dans une mosquée et confiés aux fidèles à des fins thérapeutiques. Elle procède à une analyse savante des textes gravés et traite du mode d'emploi de ces objets. Liliane Kuczynski analyse le parcours d'une jeune consultante parisienne, désespérée par la perte de l'aimé, confrontée aux marabouts de toute catégorie qu'elle a été amenée à consulter. C'est le récit d'une aventure où le décalage culturel entretient quelques malentendus. L'auteur commente plusieurs amulettes conservées par la consultante. Enfin, en dépit des spéculations habituelles qui entourent ce chiffre, le dernier chapitre porte le chiffre 13. Moussa Khedimellah y étudie le recours à la ruqiya, technique de traitement d'une maladie par la récitation de versets du Coran, qui est utilisée par un imâm guérisseur 
en Lorraine, et il pose des questions théoriques sur la fonction de ce personnage. Rien d'occulte dans une telle démarche, puisque celle-ci se veut héritière de la médecine prophétique, al-tibb al-nabâwî, et qu'elle s'exerce dans une mosquée.

6 L'auteur de ces lignes s'interroge, pour conclure, sur les rapports entre magie islamique et soufisme. Ces deux disciplines comportent une forte dimension secrète et, sauf dans des versions " sauvages ", exigent une chaîne de transmission de maître à disciple pour un exercice autorisé. Nombre de cheikh de tariqa et leurs disciples, au sud comme au nord du Sahara, donnent des consultations, interprètent les rêves et fournissent des protections. La guidance du fidèle dans la voie vers Dieu ne peut donc être séparée de ces moyens habiles qui constituent l'arsenal de la magie islamique. Soufisme et magie islamique composent un imaginaire partagé et répondent à une demande de surnaturel, de merveilleux et de guérison de l'âme. 